\title{
Smoking cessation in Asians: focus on varenicline
}

This article was published in the following Dove Press journal:

Patient Preference and Adherence

13 April 2015

Number of times this article has been viewed

\author{
Dan Xiao* \\ Shuilian Chu* \\ Chen Wang \\ Clinical Cessation and Tobacco \\ Medicine Research Centre, China- \\ Japan Friendship Hospital, Beijing, \\ People's Republic of China \\ *These authors are the co-first \\ authors
}

Correspondence: Chen Wang

Clinical Cessation and Tobacco Medicine Research Centre, China-Japan Friendship Hospital, No 2 East Street, Ying-HuaYuan, Chaoyang District, Beijing 100029, People's Republic of China

Tel +861085231610

Fax $+86106591 \quad 1810$

Email cyh-birm@263.net

\begin{abstract}
Smoking is a modifiable risk factor for morbidity and mortality caused by cancer, cardiovascular diseases, respiratory diseases, and many other diseases. Given the large population size and high prevalence of smoking in Asia, successful smoking cessation could potentially prevent the large number of premature deaths in Asians. However, most dependent smokers cannot successfully quit smoking due to nicotine addiction, and they need professional help and smoking cessation therapies. Varenicline is a highly selective partial agonist for the nicotinic acetylcholine receptor $\alpha_{4} \beta_{2}$ subtype, which is believed to be responsible for mediating the reinforcing properties of nicotine. This article is a narrative review, which summarizes the smoking cessation efficacy, side effects, and cost utilities of varenicline in Asians. From this review, we conclude that varenicline is an effective medication that could assist smoking cessation in the Asian populations. The adverse events of varenicline are tolerable, and the most common events were nausea and abnormal dreams. Both the efficacy and tolerance of varenicline in Asians are similar to that in Western populations. Considering the cost utilities, varenicline should be recommended for use in smoking cessation and be covered by medical insurance in most Asian countries.
\end{abstract}

Keywords: effectiveness, safety, cost efficacy

\section{Introduction}

Smoking is a modifiable risk factor for morbidity and mortality caused by cancer, cardiovascular diseases, respiratory diseases, and many other diseases. According to the World Health Organization, tobacco kills nearly six million people each year. ${ }^{1}$

The top ten biggest tobacco-consuming countries in the world include seven countries in Asia, with the People's Republic of China at number one and India at number two..$^{2-7}$ In 2010, there were an estimated 301 million current smokers in the People's Republic of China, with an estimated $28.1 \%$ of adult $(52.9 \%$ of men and $2.4 \%$ of women) current smokers. ${ }^{2}$ In India, the prevalence of smoking among men increased from $29.3 \%$ in 1998 to $36.4 \%$ in 2010 , with $20.3 \%$ of women and $47.9 \%$ of men aged 15 and above smoking cigarettes or bidis. ${ }^{4}$

Given the large population size and high prevalence of smoking in Asia, ${ }^{2-7}$ successful abstinence could potentially prevent the large number of premature deaths in this part of the world. Even when smokers are fully aware of the health hazards, most smokers intend to quit but cannot successfully quit smoking due to nicotine addiction. ${ }^{8}$ Thus, nicotine-dependent smokers need professional assistance and smoking cessation treatment to quit successfully. Currently, smoking cessation treatments that can markedly increase long-term abstinence rates include pharmacotherapy, smoking cessation advice, and quitlines. ${ }^{9}$ The 2008 US Guide to Quitting Smoking recommends that, except for groups with contraindications or for whom smoking cessation drugs have uncertain efficacy (eg, users of smokeless tobacco, light smokers, pregnant women, nursing women, and teenagers), clinicians should encourage all smokers intending to quit smoking to take smoking cessation medications combined with smoking cessation advice. ${ }^{9}$ 
Varenicline is a highly selective partial agonist for the nicotinic acetylcholine receptor $\alpha_{4} \beta_{2}$ subtype, which is believed to be responsible for mediating the reinforcing properties of nicotine. It has bidirectional adjustment effects of stimulation and antagonism. After combining with nicotinic acetylcholine receptors, varenicline works as an agonist, stimulating the release of dopamine in the brain, which can relieve nicotine withdrawal symptoms. Its antagonistic features can also prevent nicotine from combining with nicotinic acetylcholine receptors, thus reducing the satisfaction and reward of smoking. ${ }^{10}$ It has been approved in over 100 countries worldwide, and involved in several smoking cessation guidelines as a first-line smoking cessation medication, including the China Smoking Cessation Guideline. ${ }^{9,11}$ This article reviews the smoking cessation efficacy, adverse events (AEs), and cost utilities of varenicline in the Asian population.

\section{Methods}

\section{Literature search strategies}

This review is a narrative review, which entailed computerbased searches of Medline and the Cochrane Library to identify studies evaluating varenicline for tobacco cessation in Asians. The search covered June 2007 to July 2014, and included articles available online ahead of print publication. The search strings were "varenicline", "smoking cessation", "Asian", "Chinese OR China or Taiwan", "Japanese OR Japan”, "Korean OR Korea", "Indian OR India”, "Philippines", "Thailand", "Vietnam", and other Asian country names (though these obtained no related literature). Types of studies included meta-analysis, clinical randomized controlled trials, observational studies, and other related studies.

\section{Inclusion criteria}

The studies were required to meet the following criteria: (i) the subjects should be Asians, (ii) the full original text should be accessible, and (iii) the contents of the study should include the relationship between varenicline and smoking cessation.

\section{Results}

\section{Efficacy of smoking cessation in Asian populations}

Clinical trials in Western populations indicated that varenicline could reduce the urge and desire to smoke, and satisfaction from smoking. ${ }^{12-14}$ The results of the studies in Asians were roughly the same as those for Western populations. ${ }^{15,16}$ In a 12-week, randomized, placebo-controlled, doseresponse study, with a 40-week follow-up, mean scores in
Japanese smokers on the Minnesota Nicotine Withdrawal Scale (MNWS) Urge to Smoke subscale were significantly lower with varenicline $0.25,0.5,1 \mathrm{mg}$ twice daily compared to placebo $(P=0.01, P<0.001$, and $P<0.001)$, and indicated less negative affect $(P=0.046, P<0.001$, and $P<0.001)$ and less restlessness $(P=0.018, P<0.001$, and $P<0.001)$. Results for the mean Brief Questionnaire on Smoking Urges (QSUBrief) scores suggested a similar effect of varenicline on the QSU-Brief total craving score to that observed by the MNWS. ${ }^{15}$ Another trial conducted in Korea and Taiwan obtained similar results. ${ }^{16}$

The efficacy of varenicline as a smoking cessation aid has been reported in a number of studies. ${ }^{17-20}$ A Cochrane meta-analysis indicated that the risk ratio of continuous abstinence rates (CARs) of smokers taking standard doses of varenicline for 6 months or longer was 2.27 times that of smokers taking placebo, and 1.52 times that of smokers taking bupropion sustained-release tablets. ${ }^{17}$ Additionally, in studies where smokers taking varenicline could adjust the dosage schedule ${ }^{18}$ or choose a flexible quit date approach, ${ }^{19}$ the medication remained an effective smoking cessation aid. Prolonging treatment time with varenicline in smokers who were abstinent for the last week of treatment during the initial 12-week course increased the long-term smoking cessation rate and prevented relapse. ${ }^{20}$ Studies have also found that smoking cessation efficacy of varenicline is better than bupropion or nicotine replacement therapy (NRT) at the end of the treatment period. ${ }^{12,13,21}$

Clinical studies on smoking cessation efficacy of varenicline in Asians indicate that varenicline can markedly increase the smoking cessation rate in this population. 12,15,16,22,23 In our primary clinical trial, which was a 24 -week, randomized, double-blind, placebo-controlled trial of varenicline conducted in 333 subjects in the People's Republic of China, Singapore, and Thailand, 4-week continuous abstinence was achieved by $50.3 \%$ and $31.6 \%$ of participants in the varenicline and placebo groups, respectively $(P=0.0003)$. Continuous abstinence from weeks 9 to 24 was achieved by $38.2 \%$ and $25.0 \%$ of participants in the varenicline and placebo groups, respectively $(P=0.0080){ }^{22}$ Comparable efficacy between Japanese and the US smokers has been reported in a study of 618 Japanese smokers. This study reported a complete abstinence rate of $65.4 \%$ for varenicline at weeks 9-12, which compared well to the $44 \%$ abstinence rate reported in the US studies. ${ }^{12}$ Fagerström et al summarized and analyzed three placebo-controlled trials conducted in six Asian countries and found that 9-12-week CAR $(58.6 \%$ vs $34.3 \%$, odds ratio $[\mathrm{OR}]=2.74, P<0.0001)$ and 
9-24-week CAR (41.4\% vs 25.3\%, OR $=2.08, P<0.0001)$ for the varenicline group were both higher than for the placebo group. ${ }^{23}$

A double-blind, placebo-controlled, randomized trial in India found that varenicline was also effective for treating smokeless tobacco dependence. Although biochemically confirmed abstinence was greater for varenicline vs placebo $(25.2 \%$ vs $19.5 \%)$, this was not statistically different (adjusted $\mathrm{OR}=1.6,95 \%$ confidence interval [CI], 0.84-3.1, $P=0.15) .{ }^{24}$ Further studies are required to confirm the effectiveness of varenicline in this specific population.

The results of an observational study on the efficacy of varenicline in Asians obtained similar findings as randomized trials. An observational study in adult Filipino smokers prescribed varenicline for the first time (during routine clinical practice) indicated that varenicline was efficacious as an aid for smoking cessation. At the end of week 12, 57.6\% (95\% CI, 52.0\%-63.0\%) of participants had been abstinent in the previous 7 days. ${ }^{25}$ A smoking cessation program for outpatients, provided by a hospital in Southern Taiwan, found that varenicline use in a sample of treatment-seeking dependent smokers was associated with significantly higher abstinence rates than the nicotine patch. ${ }^{26} \mathrm{~A}$ real-world observational study in a smoking cessation clinic in Taiwan, which involved 587 smokers followed up at 3 years, found that 36-month sustained abstinence rates showed a significant advantage for varenicline than for the nicotine patch $(\mathrm{OR}=7.94,95 \% \mathrm{CI}, 1.87-33.74) .{ }^{27}$ A multicenter, prospective, non-comparative, observational study conducted in the People's Republic of China, India, Philippines, and Korea demonstrated an acceptable safety profile of varenicline, and the abstinence rates was consistent with those of randomized controlled trials. Overall, 46.4\% (95\% CI, $43.73 \%-49.07 \%$ ) of subjects successfully quit smoking by the end of the treatment phase at week $12 .{ }^{28}$ However, the compliance to medication use in the real world must be considered. An observational study conducted in a pulmonary clinic in South Korea found that although varenicline was effective in reducing the desire to smoke, compliance with medication was poor, and this needs to be overcome in clinical practice. ${ }^{29}$

\section{Safety and tolerance in Asian populations}

Many studies have showed that the safety and tolerance of varenicline during clinical treatment are relatively good. The most common AEs reported are nausea and strange dreams. ${ }^{15,16,18,19}$ The tolerability of varenicline in Asians is generally consistent with that of Western populations. ${ }^{22-28} \mathrm{In}$ our primary clinical trial, the most frequent categories of AEs were gastrointestinal disorders, psychiatric disorders, nervous system disorders, general disorders, and administration site conditions, infections, and infestations. The most common AEs reported were nausea and strange dreams. ${ }^{22}$ A clinical trial conducted among Chinese, Thai, and Singaporean smokers showed that the most commonly reported AEs in the varenicline group were nausea (29.1\%), dizziness (14.5\%), dry mouth $(9.1 \%)$, and insomnia and drowsiness (both $6.1 \%$ ). ${ }^{23}$ The results of an observational study in adult Filipino smokers prescribed varenicline for the first time demonstrated that the most frequently reported AEs were headache $(5.5 \%)$, dizziness $(3.9 \%)$, and nausea $(3.6 \%){ }^{25}$

Some post-marketing reports have drawn attention to neuropsychiatric AEs found in patients taking varenicline. ${ }^{30-32}$ In February 2008, the US Food and Drug Administration announced that the psychiatric symptoms reported by patients who took varenicline include behavioral changes, agitation, sadness, suicidal thoughts, and suicide attempts or deaths. Prescribing information for varenicline was subsequently updated in the US, Europe, and the People's Republic of China to include warnings about neuropsychiatric events for doctors and patients. However, data from randomized, placebo-controlled studies, retrospective cohort studies, and a prospective cohort study of varenicline in patients without active mental disorders have not shown an increase in neuropsychiatric AEs. ${ }^{33-38}$ Many randomized, double-blind, placebo-controlled studies have reported no evidence of exacerbation of symptoms in patients with mental disease, and varenicline was not associated with significantly higher smoking cessation rates vs placebo. ${ }^{39-42}$ Within the Asian population, varenicline has not been reported to be associated with increasing psychiatric symptoms or suicide, ${ }^{22-29}$ though further trials are needed to confirm this.

Three systematic reviews by Singh et al, Prochaska and Hilton, and Ware et al published between 2011 and 2013, have evaluated serious cardiovascular AEs with varenicline use. ${ }^{43-45}$ Even though all three reviews demonstrated that serious cardiovascular AEs were nominally more frequent in varenicline-treated patients when compared to placebo, a significantly increased event rate was found only in the review by Singh et al. ${ }^{43}$ The three reviews included similar trials but differed in the evaluation of outcomes and performance of summary statistic computation. In a clinical trial conducted in 85 Japanese smokers, the researchers evaluated the effect of varenicline-assisted smoking cessation on vascular endothelial function assessed by flow-mediated vasodilation (FMD). Participants were evaluated by FMD prior to, and 3 months after, complete smoking cessation. The researchers found that FMD was significantly increased from 
$4.0 \% \pm 1.8 \%$ to $5.5 \% \pm 2.2 \%(P<0.01, \mathrm{n}=22) 3$ months after complete cessation. FMD also increased during varenicline use (from $3.7 \% \pm 2.7 \%$ to $4.3 \% \pm 2.8 \%, n=11$ ). The observations suggest that in ceasing smokers, varenicline and smoking cessation do not lead to worsening of the vascular endothelial function. ${ }^{46}$ Within the Asian population, there have been no reports of varenicline being associated with increasing serious cardiovascular AEs, ${ }^{22-29}$ though further trials are needed to confirm this.

\section{Cost efficacy of varenicline}

Since in most Asian countries, smokers would purchase varenicline themselves, the cost utility of varenicline must be evaluated. A cost-utility analysis of two 12-week smoking cessation interventions in Japan (smoking cessation counseling by a physician vs varenicline in addition to counseling) analyzed lifetime medical costs and quality-adjusted life-years (QALYs) from the perspective of the health care payer. It was found that varenicline would save Japanese yen 43,846 (\$US 381; \$US 1 = yen 115; October 2007) in direct medical costs and generate an increase of 0.094 QALYs in male smokers. In females, the incremental cost-effectiveness ratio was yen 346,143 per QALY gained. Varenicline was estimated to save yen 23.7 billion (\$US 206 million) of the medical costs for tobacco-associated diseases for the whole population. Overall savings were reported to be yen 9.5 billion. This study concluded that varenicline appears to be cost-effective and may contribute to future medical cost savings in Japan. ${ }^{47}$

Another similar study conducted in South Korea evaluated the cost-effectiveness of varenicline compared to other smoking cessation interventions, bupropion, NRT, and willpower. The incremental cost-effectiveness ratio for varenicline vs NRT was reported to be \$US 4,809 per QALY over a lifetime. ${ }^{48}$

However, studies conducted in Vietnam found that varenicline did not fall within the range of being "costeffective" under different scenarios. They revealed that prices of pharmaceuticals must be substantially lower than the levels from other countries if pharmacological therapies are to be cost-effective in Vietnam. ${ }^{49}$

\section{Discussion}

Meta-analyses indicate that varenicline is more effective than bupropion and single-form NRT for smoking cessation. Pooled analysis and many placebo-controlled, randomized trials and real-world studies also strongly suggest that varenicline is an effective drug that assists in smoking cessation in Asians. Moreover, varenicline was recommended in the China Smoking Cessation Guideline as a first-line smoking cessation medication in $2007 .^{11}$

The safety and tolerance of varenicline during clinical use are relatively good, and the most common AEs in clinical trials were nausea and abnormal dreams, which are similar to the AEs reported in the Western population. Although several clinical case reports suggested that varenicline might be associated with neuropsychiatric events or serious cardiovascular events, there is no evidence that varenicline was associated with a higher rate of, or an exacerbation of, mental diseases, or increasing serious cardiovascular AEs in Asians. Further trials are needed to confirm these reports.

Half of the current Asian smokers, most of whom are young men at present, will die prematurely due to smokingrelated diseases in the next few decades. Given its high cost efficacy and safety profile, varenicline should be recommended for use in smoking cessation, and be covered by medical insurance in most Asian countries.

\section{Disclosure}

Chen Wang and Dan Xiao have consulted for a number of companies with an interest in clinical trials of medication and medical professionals training for tobacco dependence treatments, including Pfizer Inc., and they have been investigators for Pfizer-sponsored clinical trials. Shuilian Chu reports no conflicts of interest in this work.

\section{References}

1. Factsheet on Tobacco. 2014. Available from: http://www.who.int/ mediacentre/factsheets/fs339/en/. Accessed November 25, 2014.

2. Li Q, Hsia J, Yang G. Prevalence of smoking in China in 2010. N Engl J Med. 2011;364(25):2469-2470.

3. Banerjee A. Tobacco use patterns among military recruits. Med J Armed Forces India. 2000;56:192-194.

4. Ministry of Health and Family Welfare, Government of India. Global Adult Tobacco Survey, India Report 2009-2010. Mumbai: Ministry of Health and Family Welfare, Government of India; 2010.

5. Korean Ministry of Health and Welfare. Smoking Survey 1988-2007 [in Korean]. Seoul: Korean Ministry of Health and Welfare; 2007.

6. Lim MK, Soh CS, Tan YS, Leong CK. Smoking in the Singapore armed forces. Singapore Med J. 1997;38(2):50-53.

7. Levy DT, Benjakul S, Ross H, Ritthiphakdee B. The role of tobacco control policies in reducing smoking and deaths in a middle income nation: results from the Thailand SimSmoke simulation model. Tob Control. 2008;17(1):53-59.

8. Baillie AJ, Mattick RP, Hall W. Quitting smoking: estimation by metaanalysis of the rate of unaided smoking cessation. Aust J Public Health. 1995;19(2):129-131.

9. Clinical Practice Guideline Treating Tobacco Use and Dependence 2008 Update Panel, Liaisons, and Staff. A clinical practice guideline for treating tobacco use and dependence: 2008 update. A U.S. public health service report. Am J Prev Med. 2008;35(2):158-176.

10. Coe JW, Brooks PR, Vetelino MG, et al. Varenicline: an alpha4beta2 nicotinic receptor partial agonist for smoking cessation. J Med Chem. 2005;48(10):3474-3477. 
11. Wang C, Xiao D. The Clinical Guidelines for Smoking Cessation in China. Beijing: WHO Collaborating Centre for Tobacco or Health, Chinese Centre for Disease Control and Prevention, Tobacco Control Office, Chinese Association on Tobacco Control Hospital Tobacco Control Professional Committee; 2007.

12. Gonzales D, Rennard SI, Nides M, et al; Varenicline Phase 3 Study Group. Varenicline, an alpha4beta2 nicotinic acetylcholine receptor partial agonist, vs sustained-release bupropion and placebo for smoking cessation: a randomized controlled trial. JAMA. 2006; 296(1):47-55.

13. Jorenby DE, Hays JT, Rigotti NA, et al; Varenicline Phase 3 Study Group. Efficacy of varenicline, an alpha4beta2 nicotinic acetylcholine receptor partial agonist, vs placebo or sustained-release bupropion for smoking cessation: a randomized controlled trial. JAMA. 2006;296(1):56-63.

14. West R, Baker CL, Cappelleri JC, Bushmakin AG. Effect of varenicline and bupropion SR on craving, nicotine withdrawal symptoms, and rewarding effects of smoking during a quit attempt. Psychopharmacology (Berl). 2008;197(3):371-377.

15. Nakamura M, Oshima A, Fujimoto Y, Maruyama N, Ishibashi T, Reeves KR. Efficacy and tolerability of varenicline, an alpha4beta2 nicotinic acetylcholine receptor partial agonist, in a 12-week, randomized, placebo-controlled, dose- response study with 40-week follow-up for smoking cessation in Japanese smokers. Clin Ther 2007;29(6):1040-1056.

16. Tsai ST, Cho HJ, Cheng HS, et al. A randomized, placebo-controlled trial of varenicline, a selective alpha4beta2 nicotinic acetylcholine receptor partial agonist, as a new therapy for smoking cessation in Asian smokers. Clin Ther. 2007;29(6):1027-1039.

17. Cahill K, Stead LF, Lancaster T. Nicotine receptor partial agonists for smoking cessation. Cochrane Database Syst Rev. 2012;4:CD006103.

18. Niaura R, Hays JT, Jorenby DE, et al. The efficacy and safety of varenicline for smoking cessation using a flexible dosing strategy in adult smokers: a randomized controlled trial. Curr Med Res Opin. 2008;24(7):1931-1941.

19. Rennard S, Hughes J, Cinciripini PM, et al; Flexible Quit Date Study Group. A randomized placebo-controlled trial of varenicline for smoking cessation allowing flexible quit dates. Nicotine Tob Res. 2012;14(3):343-350.

20. Tonstad S, Tønnesen P, Hajek P, Williams KE, Billing CB, Reeves KR. Varenicline phase 3 study group. Effect of maintenance therapy with varenicline on smoking cessation: a randomized controlled trial. JAMA. 2006;296(1):64-71.

21. Kotz D, Brown J, West R. Effectiveness of varenicline versus nicotine replacement therapy for smoking cessation with minimal professional support: evidence from an English population study. Psychopharmacology (Berl). 2014;231(1):37-42.

22. Wang C, Xiao D, Chan KP, Pothirat C, Garza D, Davies S. Varenicline for smoking cessation: a placebo-controlled, randomized study. Respirology. 2009;14(3):384-392.

23. Fagerström K, Nakamura M, Cho HJ, et al. Varenicline treatment for smoking cessation in Asian populations: a pooled analysis of placebocontrolled trials conducted in six Asian countries. Curr Med Res Opin. 2010;26(9):2165-2173.

24. Jain R, Jhanjee S, Jain V, et al. A double-blind placebo-controlled randomized trial of varenicline for smokeless tobacco dependence in India. Nicotine Tob Res. 2014;16(1):50-57.

25. Park PW, Casiano EM, Escoto L, Claveria AM. Observational study of safety and efficacy of varenicline for smoking cessation among Filipino smokers. Curr Med Res Opin. 2011;27(10):1869-1875.

26. Hsueh SC, Hsueh KC, Chou MY, Tu MS. A comparison of the effectiveness of varenicline and transdermal nicotine patch in outpatients following a standardized smoking cessation program in Southern Taiwan. Eval Health Prof. Epub 2012 Dec 4.

27. Hsueh KC, Hsueh SC, Chou MY, et al. Varenicline versus transdermal nicotine patch: a 3-year follow-up in a smoking cessation clinic in Taiwan. Psychopharmacology (Berl). 2014;231(14):2819-2823.
28. Wang C, Cho B, Xiao D, Wajsbrot D, Park PW. Effectiveness and safety of varenicline as an aid to smoking cessation: results of an inter-Asian observational study in real-world clinical practice. Int J Clin Pract. 2013;67(5):469-476.

29. Jung JW, Jeon EJ, Kim JG, et al. Clinical experience of varenicline for smoking cessation. Clin Respir J. 2010;4(4):215-221.

30. Freedman R. Exacerbation of schizophrenia by varenicline. Am $J$ Psychiatry. 2007;164(8):1269.

31. Kohen I, Kremen N. Varenicline-induced manic episode in a patient with bipolar disorder. Am J Psychiatry. 2007;164(8):1269-1270.

32. Popkin MK. Exacerbation of recurrent depression as a result of treatment with varenicline. Am J Psychiatry. 2008;165(6):774.

33. Garza D, Murphy M, Tseng LJ, Riordan HJ, Chatterjee A. A doubleblind randomized placebo-controlled pilot study of neuropsychiatric adverse events in abstinent smokers treated with varenicline or placebo. Biol Psychiatry. 2011;69(11):1075-1082.

34. Tonstad S, Davies S, Flammer M, Russ C, Hughes J. Psychiatric adverse events in randomized, double-blind, placebo-controlled clinical trials of varenicline: a pooled analysis. Drug Saf. 2010;33(4):289-301.

35. Gunnell D, Irvine D, Wise L, Davies C, Martin RM. Varenicline and suicidal behaviour: a cohort study based on data from the general practice research database. BMJ. 2009;339:b3805.

36. Stapleton JA, Watson L, Spirling LI, et al. Varenicline in the routine treatment of tobacco dependence: a pre-post comparison with nicotine replacement therapy and an evaluation in those with mental illness. Addiction. 2008;103(1):146-154.

37. Thomas KH, Martin RM, Davies NM, Metcalfe C, Windmeijer F, Gunnell D. Smoking cessation treatment and risk of depression, suicide, and self harm in the clinical practice research datalink: prospective cohort study. BMJ. 2013;347:f5704.

38. Pasternak B, Svanström H, Hviid A. Use of varenicline versus bupropion and risk of psychiatric adverse events. Addiction. 2013;108(7): 1336-1343.

39. Chengappa KN, Perkins KA, Brar JS, et al. Varenicline for smoking cessation in bipolar disorder: a randomized, double-blind, placebocontrolled study. J Clin Psychiatry. 2014;75(7):765-772.

40. Evins AE, Cather C, Pratt SA, et al. Maintenance treatment with varenicline for smoking cessation in patients with schizophrenia and bipolar disorder: a randomized clinical trial. JAMA. 2014;311(2):145-154.

41. Anthenelli RM, Morris C, Ramey TS, et al. Effects of varenicline on smoking cessation in adults with stably treated current or past major depression: a randomized trial. Ann Intern Med. 2013;159(6):390-400.

42. Williams JM, Anthenelli RM, Morris CD, et al. A randomized, doubleblind, placebo-controlled study evaluating the safety and efficacy of varenicline for smoking cessation in patients with schizophrenia or schizoaffective disorder. J Clin Psychiatry. 2012;73(5):654-660.

43. Singh S, Loke YK, Spangler JG, Furberg CD. Risk of serious adverse cardiovascular events associated with varenicline: a systematic review and meta-analysis. CMAJ. 2011;183(12):1359-1366.

44. Prochaska JJ, Hilton JF. Risk of cardiovascular serious adverse events associated with varenicline use for tobacco cessation: systematic review and meta-analysis. BMJ. 2012;344:e2856.

45. Ware JH, Vetrovec GW, Miller AB, et al. Cardiovascular safety of varenicline: patient-level meta-analysis of randomized, blinded, placebo-controlled trials. Am J Ther. 2013;20(3):235-246.

46. Umeda A, Kato T, Yamane T, et al. Does smoking cessation with varenicline worsen vascular endothelial function? BMJ Open. 2013; 3(6): 003052.

47. Igarashi A, Takuma H, Fukuda T, Tsutani K. Cost-utility analysis of varenicline, an oral smoking-cessation drug, in Japan. Pharmacoeconomics. 2009;27(3):247-261.

48. Bae JY, Kim CH, Lee EK. Evaluation of cost-utility of varenicline compared with existing smoking cessation therapies in South Korea. Value Health. 2009;12(suppl 3):S70-S73.

49. Higashi H, Barendregt JJ. Cost-effectiveness of tobacco control policies in Vietnam: the case of personal smoking cessation support. Addiction. 2012;107(3):658-670. 
Patient Preference and Adherence

Dovepress

\section{Publish your work in this journal}

Patient Preference and Adherence is an international, peer-reviewed, open access journal that focuses on the growing importance of patient preference and adherence throughout the therapeutic continuum. Patient satisfaction, acceptability, quality of life, compliance, persistence and their role in developing new therapeutic modalities and compounds to optimize

clinical outcomes for existing disease states are major areas of interest for the journal. This journal has been accepted for indexing on PubMed Central. The manuscript management system is completely online and includes a very quick and fair peer-review system, which is all easy to use. Visit http://www. dovepress.com/testimonials.php to read real quotes from published authors.

Submit your manuscript here: http://www.dovepress.com/patient-preference-and-adherence-journal 